\title{
Addition to the RAND HRS Longitudinal Files: IRA Withdrawals in the HRS, 2000 to 2014
}

Michael D. Hurd, Erik Meijer, Philip Pantoja, and Susann Rohwedder

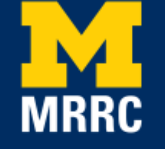

Project \#: R-UM18-Q3 


\title{
Addition to the RAND HRS Longitudinal Files: IRA Withdrawals in the HRS, 2000 to 2014
}

\author{
Michael D. Hurd \\ RAND \\ Erik Meijer \\ RAND and University of Southern California \\ Philip Pantoja \\ RAND \\ Susann Rohwedder \\ RAND
}

October 2018

\author{
Michigan Retirement Research Center \\ University of Michigan \\ P.O. Box 1248 \\ Ann Arbor, MI 48104 \\ www.mrrc.isr.umich.edu
}

(734) 615-0422

\section{Acknowledgements}

The research reported herein was performed pursuant to a grant from the U.S. Social Security Administration (SSA) funded as part of the Retirement Research Consortium through the University of Michigan Retirement Research Center Award RRC08098401-10. The opinions and conclusions expressed are solely those of the author(s) and do not represent the opinions or policy of SSA or any agency of the federal government. Neither the United States government nor any agency thereof, nor any of their employees, makes any warranty, express or implied, or assumes any legal liability or responsibility for the accuracy, completeness, or usefulness of the contents of this report. Reference herein to any specific commercial product, process or service by trade name, trademark, manufacturer, or otherwise does not necessarily constitute or imply endorsement, recommendation or favoring by the United States government or any agency thereof.

\section{Regents of the University of Michigan}

Michael J. Behm, Grand Blanc; Mark J. Bernstein, Ann Arbor; Shauna Ryder Diggs, Grosse Pointe; Denise Ilitch, Bingham Farms; Andrea Fischer Newman, Ann Arbor; Andrew C. Richner, Grosse Pointe Park; Ron Weiser, Ann Arbor; Katherine E. White, Ann Arbor; Mark S. Schlissel, ex officio 


\title{
Addition to the RAND HRS Longitudinal Files: IRA Withdrawals in the HRS, 2000-2014
}

\begin{abstract}
In support of research on the older population, we produced cleaned variables based on data from the Health and Retirement Study (HRS) to capture information on withdrawals from individual retirement accounts (IRAs). Where necessary, imputations for missing values have been performed using methods consistent with those employed in the RAND HRS. To facilitate analyses of retirement resources, we also included approximations of annualized IRA withdrawal amounts. The cleaning and derivation of the new variables has been fully integrated into the RAND HRS production process so that maintenance and the addition of future waves can be achieved with relatively small effort. Construction of the new variables for HRS waves 2000 to 2014 has been completed; the corresponding variables for HRS 2016 are currently being processed along with the entire HRS 2016 core data. The full set of new IRA withdrawal variables (HRS waves 2000 to 2016) will be made available to the research community with the next release of the RAND HRS Longitudinal File, including detailed documentation as part of the accompanying codebook. Based on these new variables, we found that about 16 percent of HRS households withdrew money from their IRA accounts since the last interview, and conditional on making a withdrawal, the average total withdrawal amount is about $\$ 23,000$ in the later HRS waves.
\end{abstract}

\section{Citation}

Hurd, Michael D., Erik Meijer, Philip Pantoja and Susann Rohwedder. 2018. "Addition to the RAND HRS Longitudinal Files: IRA Withdrawals in the HRS, 2000-2014," Ann Arbor MI: University of Michigan Retirement Research Center (MRRC) Working Paper, WP 2018-388. https://mrdrc.isr.umich.edu/publications/papers/pdf/wp388.pdf 


\section{Introduction}

Financial preparation for retirement has increasingly involved saving in tax-advantaged retirement accounts. Individuals who accumulate defined contribution pension balances are encouraged to roll these over to an IRA upon separation from their employer. Others may have been eligible to contribute to an IRA at various times in their lives. As a result, households hold substantial financial resources in IRA accounts: 49 percent of married households and 27 percent of single households own such accounts, according to HRS 2014. The average balances amount to $\$ 133 \mathrm{k}$ for married households and $\$ 37 \mathrm{k}$ for single households (including zeros). As is the case with other wealth components, the distribution of balances is skewed. The $90^{\text {th }}$ percentile value among married households is $\$ 400 \mathrm{k}$; among single households, the $90^{\text {th }}$ percentile value is $\$ 100 k$.

Funds held in IRAs are intended to finance spending at older ages and as such to augment retirement incomes. However, common definitions of income do not include such withdrawals in income. Some have argued that this is likely to result in misleading assessments of the financial situation of the older population, especially in studies that focus exclusively on income, without taking into account information on household assets (Iams and Purcell, 2013). The same arguments apply to withdrawals from pension accounts held in forms other than IRAs.

The Health and Retirement Study (HRS) is the primary data set to study the financial position of older households in the U.S. It collects rich data on assets and income, including information on pensions, IRAs, and Keogh accounts. The information on pensions has undergone various changes over the years, and this poses numerous measurement challenges. However, the information that HRS collects on IRA/Keogh balances and withdrawals has been relatively stable. Nevertheless, HRS survey data on IRA withdrawals have not been used much 
in analyses, in part because these are difficult to process, difficult to compare to income that is measured for the calendar year, and the information is not currently included in the RAND HRS Longitudinal File.

\section{Measurement of IRA Withdrawals in the HRS}

The HRS elicits information on whether households own any individual retirement accounts and asks related follow-up questions in the Assets and Income section (Section Q) of the survey. In married or partnered households, the financial respondent answers all questions in this section on behalf of both the respondent and the spouse. From HRS 2000 (Wave 5) forward, the IRA questions follow the same basic structure:

"Do you (or your husband/wife/partner) currently have any money or assets that are held in an Individual Retirement Account, that is, in an IRA or KEOGH account?", (Yes, No, Don't know, Refuse)

"How many IRA or KEOGH accounts do you (and your husband/wife/partner) have?"

(Number, Don't know, Refuse)

The following sequence is then asked up to three times, depending on how many IRA or Keogh accounts were reported. Respondents are first asked about the largest, followed by the next largest, and the third or — if the household owns more than three — all other IRA or Keogh accounts, if applicable.

\footnotetext{
"Are these / Is that yours or your [husband's/wife's/partner's]?”

"About how much (in total) is in this (these [other] IRA or KEOGH) account(s) at the present time?" \$
} 
If the respondent refuses or does not know the value, a series of unfolding bracket questions $^{1}$ are asked. Later, respondents are asked about IRA withdrawals:

"Have you (or your [husband/wife/partner]) withdrawn any money or received any payments from [this account/these accounts] [since R's last interview / in the last two years]?"

"Altogether, about how much money did you (or your [husband/wife/partner])

withdraw from [this account/these accounts] [since R's last interview / in the last two years], (before taxes and other deductions)?"

Again, if the respondent refuses or does not know the value, a series of unfolding bracket questions are asked. Those who provide a continuous value are asked about the frequency of receipt, with the following recorded response options: ${ }^{2}$

1. IN TOTAL

3. $\mathrm{MONTH}$

4. QUARTER

5. $6 \mathrm{MONTH}$

6. YEAR

7. OTHER (SPECIFY)

8. $\quad$ DK (Don't Know); NA (Not Ascertained)

9. $\quad R F$ (Refused)

Finally, respondents are asked the following question:

"Did you (or your [husband/wife/partner]) take out only the 'minimum withdrawal option, ' that is, the amount required to avoid a tax penalty?"

\footnotetext{
${ }^{1}$ These are questions of the form "Does it amount to less than \$X, more than \$X, or what?" (less, more, about, don't know, refuse). Up to three values of X (bracket thresholds) are asked. Such a sequence narrows the range of uncertainty about the value. The bracket is the resulting narrowed interval.

${ }^{2}$ For those who answer the unfolding bracket questions, the frequency question is not asked, and the bracket questions refer to the total period (since last interview or last two years).
} 
Respondents are then asked a separate set of questions about any IRA or Keogh accounts that have been cashed in or annuitized. First, they are asked:

"Did you (or your [husband/wife/partner]) cash in or convert any (other) IRA or KEOGH accounts to annuities at any time [since FINANCIAL R's LAST IW MONTH, YEAR/in the last two years]?"

Those who say "yes” are asked:

"Was that your IRA or KEOGH or your [husband's/wife's/partner's]?"

"Did you (or your [husband/wife/partner]) cash in these accounts, convert them to annuities, or what?"

Respondents who report cashing in any accounts are asked how much was withdrawn. If they refuse or do not know the value, a series of unfolding bracket questions are asked, except in HRS 2000 (Wave 5), where no such questions are present.

The information elicited in the survey allows computing for each household the total IRA withdrawal amount taken out since the last interview, or in the case of new interviews, in the last 24 months.

\section{Methods: IRA withdrawal variables for inclusion in the RAND HRS}

Variables in the RAND HRS should be derived in a way to closely capture the concept that was asked in the survey. In some cases, variations of such variables would facilitate other types of analyses. In that spirit, we derived two concepts based on the questions on withdrawals from IRA and KEOGH accounts:

\section{Household-level total IRA withdrawal amount since last interview (or in} last 24 months in the case of new interviews): sums the reported amounts (up to four) while making appropriate adjustments for the frequency (once, yearly, monthly, etc.) where necessary. 


\section{Respondent-level IRA withdrawal amount taken out in the last calendar}

year: In the case of couples, this requires the assignment of each reported IRA withdrawal amount to either the respondent or the spouse (except for the third amount and the cashed-in amount if they refer to more than one IRA, in which case it can pertain to both the respondent and spouse). To approximate the amount taken out in the last calendar year, the amounts reported in the survey instrument "since last interview" are prorated to reflect a 12-month period.

The objective of constructing an amount that approximates withdrawals for the last calendar year is to facilitate analyses that gauge the importance of these withdrawals compared to other economic resources, such as income, which is also measured for the last calendar year.

A reduced set of summary variables on total IRA withdrawals will be included in the RAND HRS Longitudinal File, and the detailed component variables will be included in the RAND HRS Detailed Imputations File (indicators for any withdrawals for household, respondent and spouse; withdrawal amounts for each of up to four IRAs; and imputation flags for the total and for each of up to four reported withdrawal amounts). See Appendix 1 for the full list of variables to be included in each of the RAND HRS data products.

\section{Imputations}

When respondents do not know or refuse to answer an item in the IRA survey sequence, we need to perform imputations of the missing items to be able to construct the IRA withdrawal variables for all observations. Imputations are performed at the household-level, using crosssectional imputation methods developed for the RAND HRS. The main items that need imputation when missing in the context of the IRA withdrawals are (i) whether the household made any withdrawals; (ii) the bracket of the missing amount; and (iii) the missing amount. The 
imputations of "any withdrawal" (i) are pseudo-random draws from a logistic regression model, the imputations of brackets (ii) are pseudo-random draws from an ordered logistic regression model, and the imputations of the amounts (iii) employ either the nearest neighbor method (also called predictive mean matching) or are pseudo-random draws from a tobit model. If enough observations are available, the imputations use a set of covariates that is formed by the first 10 principal components of approximately 30 underlying covariates. These include (transformations of) husband and wife's employment status, education, health status, age, race, marital status, occupation class, cognition, and bequest expectations. For further details on the RAND HRS imputation methods, see Hurd et al. (2016, Appendix E) and Pantoja et al. (2018, Chapter 2).

The survey instrument elicits up to three withdrawal amounts for each household, plus a fourth withdrawal amount that represents any accounts that have been cashed in. ${ }^{3}$ These are imputed separately, taking into account the reported frequency of withdrawals where necessary. In the case of couples, the next step is to assign for each withdrawal amount whether it pertains to the respondent or the spouse. To that end, we use information about ownership of the IRA (respondent, spouse, or both). If an IRA is owned by the respondent, then the IRA withdrawal is assigned to the respondent. If an IRA is owned by the spouse, then the IRA withdrawal is assigned to the spouse. IRAs are owned by individuals so joint ownership is not possible. However, the third IRA question, and the question asking about any accounts that have been cashed in, may refer to more than one IRA account (all other IRA accounts the household owns). In that case, joint ownership as measured in the HRS is possible and the withdrawal amount is divided equally between both spouses. If the information on IRA ownership is missing then it is

\footnotetext{
${ }^{3}$ The question on IRAs that may have been cashed in also allows the mention of converting some or all of the IRA to an annuity. We do not include in the withdrawal amounts any balances that were converted to an annuity. These produce an income stream that will be captured in the HRS income measure.
} 
assumed that the IRA belongs to the financial respondent as this is the modal response observed in the data.

Tax laws that govern IRA withdrawals strongly influence the patterns observed in the data. For example, there are very few withdrawals prior to the age of $59 \frac{1}{2}$ because withdrawals before that age incur a tax penalty. Similarly, many households do not make withdrawals until after they turn $70 \frac{1}{2}$ when a schedule of required minimum withdrawals (RMD) applies. Therefore, if the withdrawn IRA amount is missing, but the respondent indicated making an RMD, the missing value is replaced with the calculated RMD. See Appendix 2 for details of this calculation.

\section{Allocation of total IRA withdrawals to withdrawals from separate IRAs}

When a respondent does not provide a continuous amount for withdrawal from one or more IRA accounts (including cashed-in accounts), we impute those withdrawals. This is done separately by account. However, if in addition to not providing a complete set of continuous amounts, the respondent indicates having taken the "required minimum distribution" (RMD), we estimate the RMD for the respondent and impute a total withdrawal amount (TOTW) that is equal to the RMD if this is consistent with the respondent's (other) answers, or the nearest amount that is consistent with the respondent's other answers if the RMD is inconsistent with those. We then allocate the total withdrawal amount to the withdrawals from the (up to) four separate accounts. We do this in such a way that the allocated amounts are always consistent with what the respondent reported about the withdrawals from the separate accounts. Thus, if the respondent gave a continuous amount, this is the allocated amount, and if the respondent gave a bracket, the allocated amount is within the bracket. In many cases, this completely determines the allocations, but there are cases where there is still some flexibility in allocation. In those cases, we take the initial imputations as target amounts and allocate the total withdrawal amount 
to the separate accounts such that it minimizes the sum of squared differences between the final withdrawal amounts and the target amounts, subject to the withdrawals all being consistent with the respondent's answers. For example, if the target amounts add up to the total withdrawal amount, the final allocated amounts are equal to the target amounts. But if the total withdrawal amount was adapted because the RMD was taken, the amounts are adjusted such that they add up to the total, while staying as close as possible to the target amounts. ${ }^{4}$

\section{Approximating IRA withdrawal amounts for the last calendar year}

The HRS survey questions elicit IRA withdrawal amounts "since the last interview" or, in the case of new interviews, "in the last 24 months." However, for analyses of the importance of IRA withdrawals in the provision of economic resources in retirement, researchers will want to compare these withdrawals to income, which is generally recorded as income received last

calendar year. ${ }^{5}$ The survey questionnaire does not include sufficient information on the timing of the IRA withdrawals to determine which ones were made in the last calendar year. As an approximation, we therefore use the information on the reference period (time elapsed since last interview, or last 24 months for new interviews) to prorate the observed total withdrawals to reflect a 12-month equivalent.

\section{Data construction process}

In order to process the HRS variables related to IRA withdrawals for addition to the RAND HRS Longitudinal file, the RAND HRS team performed the following tasks:

\footnotetext{
${ }^{4}$ Mathematically, this is a quadratic programming problem subject to linear inequality restrictions, which is surprisingly complicated in its full generality. However, we were able to solve this for this particular problem using a noniterative algorithm that we have implemented in our code.

${ }^{5}$ Some components, specifically Social Security benefits, are elicited for the last calendar month, but these are also converted to last calendar year in the RAND HRS.
} 
- Extracted and assembled all required raw variables for HRS waves 2000 to 2016 (nine waves);

- Conducted consistency checks in HRS questionnaires and in the HRS raw data;

- Derived longitudinally consistent variables and assigned variable names and informative special missing values, following RAND HRS conventions;

- Performed imputations for missing values for all available waves; ${ }^{6}$

- Produced detailed documentation of variable construction, cross-wave differences and imputation methods;

- Produced summary variables of IRA withdrawals to be added to the next version of the RAND HRS Longitudinal File (total household IRA withdrawals since last interview/previous 24 months, and Respondent's and Spouse's total IRA withdrawals for the last calendar year);

- Produced component variables for IRA withdrawal amounts (first account, second, third or all others, and cashed-in accounts), and indicator variables for any withdrawals from the respective potential accounts and imputation flags.

The RAND HRS team is currently processing the 2016 wave of HRS, which was just recently released in July 2018. The IRA withdrawal variables for this latest wave will be produced along with all other RAND HRS variables. The full set of the new IRA withdrawal variables will be disseminated to the research community together with the next public release of the RAND HRS Longitudinal File and the companion Longitudinal Detailed Imputations File.

\footnotetext{
${ }^{6}$ Imputations for the HRS 2016 variables are currently in preparation, along with all other 2016 RAND HRS variables.
} 


\section{Results}

\section{Response patterns observed in the raw data and need for imputation}

Because IRA withdrawals are reported by account (first, second, third or all others, and cashed-in accounts), there are many items that could be missing and many combinations of missing patterns. Table 1 shows a household-level summary for each HRS wave from 2000 through 2014 of the fraction who reported no withdrawals, those who reported all details of their withdrawals (so no imputation was needed), and those where some imputation was required.

Overall 77-82 percent of households reported no IRA withdrawals across the 2000-2014 HRS waves. Some required imputation of whether any withdrawal was made. After imputations, the fraction of households without any withdrawals since the last HRS interview (or in last 24 months for new interviews) was between 82 and 86 percent per wave; conversely, 14 to 18 percent of households per wave made withdrawals. Conditional on making a withdrawal, the average amounts per wave range between $\$ 21$ and \$25 thousand. Households that needed at least some imputation have lower totals.

Table 2 shows information at the respondent-level, that is, after assignment to respondent or spouse in the case of couple households, prorated to reflect a 12-month equivalent, and taking the RMD into consideration (where necessary). 
Table 1. Household-level summary of survey information on IRA withdrawals since the last interview (or last 2 years) in the HRS and imputation status, unweighted.

\begin{tabular}{|c|c|c|c|c|c|c|c|c|c|c|c|c|c|c|c|c|}
\hline \multirow[b]{2}{*}{$\begin{array}{l}\text { Imputation } \\
\text { Summary }\end{array}$} & \multicolumn{4}{|c|}{2000} & \multicolumn{4}{|c|}{2002} & \multicolumn{4}{|c|}{2004} & \multicolumn{4}{|c|}{2006} \\
\hline & $\mathbf{N}$ & $\%$ & Mean & Median & $\mathbf{N}$ & $\%$ & Mean & Median & $\mathbf{N}$ & $\%$ & Mean & Median & $\mathbf{N}$ & $\%$ & Mean & Median \\
\hline $\begin{array}{l}\text { No withdrawal } \\
\text { (reported) }\end{array}$ & 10,858 & 82.2 & 0 & 0 & 10,055 & 81.4 & 0 & 0 & 11,040 & 80.9 & 0 & 0 & 9,982 & 79.2 & 0 & 0 \\
\hline $\begin{array}{l}\text { No withdrawal } \\
\text { (imputed) }\end{array}$ & 560 & 4.2 & 0 & 0 & 536 & 4.3 & 0 & 0 & 600 & 4.4 & 0 & 0 & 546 & 4.3 & 0 & 0 \\
\hline $\begin{array}{l}\text { Withdrawal } \\
\text { (reported) }^{*}\end{array}$ & 1,396 & 10.6 & 20,995 & 7,900 & 1,314 & 10.6 & 23,393 & 9,150 & 1,514 & 11.1 & 21,479 & 8,600 & 1,589 & 12.6 & 21,738 & 8,013 \\
\hline $\begin{array}{l}\text { Withdrawal } \\
\text { (imputed)^ }\end{array}$ & 400 & 3.0 & 13,931 & 5,083 & 444 & 3.6 & 15,875 & 6,333 & 491 & 3.6 & 15,269 & 4,133 & 488 & 3.9 & 14,177 & 5,000 \\
\hline \multirow[t]{2}{*}{ All } & 13,214 & 100 & 2,640 & 0 & 12,349 & 100 & 3,060 & 0 & 13,645 & 100 & 2,933 & 0 & 12,605 & 100 & 3,289 & 0 \\
\hline & \multicolumn{4}{|c|}{2008} & \multicolumn{4}{|c|}{2010} & \multicolumn{4}{|c|}{2012} & \multicolumn{4}{|c|}{2014} \\
\hline $\begin{array}{l}\text { Imputation } \\
\text { Summary }\end{array}$ & $\mathbf{N}$ & $\%$ & Mean & Median & $\mathbf{N}$ & $\%$ & Mean & Median & $\mathbf{N}$ & $\%$ & Mean & Median & $\mathbf{N}$ & $\%$ & Mean & Median \\
\hline $\begin{array}{l}\text { No withdrawal } \\
\text { (reported) }\end{array}$ & 9,201 & 77.3 & 0 & 0 & 12,034 & 78.8 & 0 & 0 & 11,475 & 80.2 & 0 & 0 & 10,391 & 78.5 & 0 & 0 \\
\hline $\begin{array}{l}\text { No withdrawal } \\
\text { (imputed) }\end{array}$ & 532 & 4.5 & 0 & 0 & 892 & 5.8 & 0 & 0 & 641 & 4.5 & 0 & 0 & 654 & 4.9 & 0 & 0 \\
\hline $\begin{array}{l}\text { Withdrawal } \\
\text { (reported) }\end{array}$ & 1,647 & 13.8 & 22,482 & 10,000 & 1,788 & 11.7 & 25,211 & 10,817 & 1,708 & 11.9 & 23,490 & 10,000 & 1,691 & 12.8 & 23,536 & 11,000 \\
\hline $\begin{array}{l}\text { Withdrawal } \\
\text { (imputed)^ }\end{array}$ & 517 & 4.3 & 21,506 & 7,958 & 566 & 3.7 & 24,650 & 9,000 & 492 & 3.4 & 20,626 & 8,909 & 505 & 3.8 & 24,457 & 10,000 \\
\hline All & 11,897 & 100 & 4,047 & 0 & 15,280 & 100 & 3,863 & 0 & 14,316 & 100 & 3,511 & 0 & 13,241 & 100 & 3,937 & 0 \\
\hline
\end{tabular}


Table 2. Respondent-level summary of survey information on IRA withdrawals in the HRS and imputation status, prorated to last calendar year, unweighted.

\begin{tabular}{|c|c|c|c|c|c|c|c|c|c|c|c|c|c|c|c|c|}
\hline \multirow[b]{2}{*}{$\begin{array}{l}\text { Imputation } \\
\text { Summary }\end{array}$} & \multicolumn{4}{|c|}{2000} & \multicolumn{4}{|c|}{2002} & \multicolumn{4}{|c|}{2004} & \multicolumn{4}{|c|}{2006} \\
\hline & $\mathbf{N}$ & $\%$ & Mean & Median & $\mathbf{N}$ & $\%$ & Mean & Median & $\mathbf{N}$ & $\%$ & Mean & Median & $\mathbf{N}$ & $\%$ & Mean & Median \\
\hline $\begin{array}{l}\text { No withdrawal } \\
\text { (reported) }\end{array}$ & 16,601 & 84.8 & 0 & 0 & 15,230 & 83.8 & 0 & 0 & 16,831 & 83.6 & 0 & 0 & 15,168 & 82.1 & 0 & 0 \\
\hline $\begin{array}{l}\text { No withdrawal } \\
\text { (imputed) }\end{array}$ & 872 & 4.5 & 0 & 0 & 875 & 4.8 & 0 & 0 & 940 & 4.7 & 0 & 0 & 886 & 4.8 & 0 & 0 \\
\hline $\begin{array}{l}\text { Withdrawal } \\
\text { (reported) }^{*}\end{array}$ & 1,651 & 8.4 & 9,205 & 3,130 & 1,544 & 8.5 & 9,274 & 3,161 & 1,787 & 8.9 & 9,279 & 3,333 & 1,859 & 10.1 & 9,342 & 3,111 \\
\hline $\begin{array}{l}\text { Withdrawal } \\
\text { (imputed)^ }\end{array}$ & 455 & 2.3 & 5,852 & 2,318 & 516 & 2.8 & 6,237 & 2,308 & 571 & 2.8 & 6,101 & 2,143 & 556 & 3.0 & 6,299 & 2,478 \\
\hline All & 19,579 & 100 & 912 & 0 & 18,165 & 100 & 965 & 0 & 20,129 & 100 & 997 & 0 & 18,469 & 100 & 1,130 & 0 \\
\hline & \multicolumn{4}{|c|}{2008} & \multicolumn{4}{|c|}{2010} & \multicolumn{4}{|c|}{2012} & \multicolumn{4}{|c|}{2014} \\
\hline $\begin{array}{l}\text { Imputation } \\
\text { Summary }\end{array}$ & $\mathbf{N}$ & $\%$ & Mean & Median & $\mathbf{N}$ & $\%$ & Mean & Median & $\mathbf{N}$ & $\%$ & Mean & Median & $\mathbf{N}$ & $\%$ & Mean & Median \\
\hline $\begin{array}{l}\text { No withdrawal } \\
\text { (reported) }\end{array}$ & 13,839 & 80.4 & 0 & 0 & 17,997 & 81.7 & 0 & 0 & 17,031 & 82.9 & 0 & 0 & 15,241 & 81.3 & 0 & 0 \\
\hline $\begin{array}{l}\text { No withdrawal } \\
\text { (imputed) }\end{array}$ & 835 & 4.8 & 0 & 0 & 1,289 & 5.9 & 0 & 0 & 928 & 4.5 & 0 & 0 & 951 & 5.1 & 0 & 0 \\
\hline $\begin{array}{l}\text { Withdrawal } \\
\text { (reported) }^{*}\end{array}$ & 1,952 & 11.3 & 9,670 & 4,000 & 2,099 & 9.5 & 9,315 & 3,972 & 2,000 & 9.7 & 11,006 & 4,235 & 1,985 & 10.6 & 10,606 & 4,800 \\
\hline $\begin{array}{l}\text { Withdrawal } \\
\text { (imputed) }\end{array}$ & 591 & 3.4 & 8,997 & 2,965 & 649 & 2.9 & 8,694 & 3,111 & 595 & 2.9 & 9,325 & 3,900 & 570 & 3.0 & 11,387 & 4,403 \\
\hline All & 17,217 & 100 & 1,405 & 0 & 22,034 & 100 & 1,143 & 0 & 20,554 & 100 & 1,341 & 0 & 18,747 & 100 & 1,469 & 0 \\
\hline
\end{tabular}

* "Withdrawal (reported)" represents those observations that made withdrawals from an IRA, and where no imputations were needed because respondents reported all the information.

$\wedge$ "Withdrawal (imputed)" represents those observations where there was missing information related to IRA withdrawals. Some were missing whether any withdrawals were made (and were imputed to "yes"), some were missing information about the withdrawn amounts, and some were missing both. 


\section{Comparison of IRA withdrawals with household income}

An important question is how important IRA withdrawals are in the context of financing retirement. To shed some light on this, Table 3 shows average IRA withdrawals for the last calendar year alongside total household income and some components of income for 72 to 77 year olds. We chose this age group, because prior to age $70 \frac{1}{2}$, fewer households make IRA withdrawals. The top two panels in Table 3 show average dollar amounts for single men and women, and the bottom panel shows the amounts for married $^{7}$ households. Total IRA withdrawal amounts for last calendar year are smaller for singles than married households, and single women have smaller withdrawals than single men. Compared to total household income, IRA withdrawals amount to about 4.9 percent of total income for singles and 6.9 percent for married households. For single men, IRA withdrawals equal about 15.2 percent of their income from Social Security and 22.9 percent of their income from pensions and annuities. For single females, these percentages are a little smaller, 11.7 percent and 19.9 percent respectively. For married households in this age group, IRA withdrawals are relatively larger when compared to Social Security income (20.6 percent) and to income from pensions and annuities (30.9 percent). Interestingly, these percentages do not exhibit any discernable trend over time. It will be important to combine the information on IRA withdrawals with information on other forms of tax-advantaged savings accounts, such as withdrawals from 401(k)s and other defined contribution pensions. It is generally perceived that these latter forms of savings have gained in importance in households' portfolios as a result of the shift from defined benefit to defined contribution pensions. When workers separate from an employer they can leave the balance in defined contribution (DC) plans to accumulate without rolling it over into an IRA. It would be

\footnotetext{
${ }^{7}$ As is common in studies based on the HRS, we include unmarried couples among the "married."
} 
important to assess IRA withdrawals jointly with withdrawals from DC accounts left with employers for any time trend. However, this analysis is beyond the scope of this project.

\section{Conclusions}

The main objective of this project was to produce cleaned variables based on data from the HRS to capture information on withdrawals from Individual Retirement Accounts. Where necessary, imputations for missing values have been performed using methods fully consistent with those employed in the RAND HRS. The resulting variables will be included in the next version of the RAND HRS Longitudinal File and the companion RAND HRS Detailed Imputations File. This will be an important addition to support research on economic preparation for retirement and resources after retirement based on the HRS data. Withdrawal amounts among 72 to 77 year olds amount to 4.9 percent of total income for single and 6.9 percent for married households. 
Table 3. IRA withdrawals compared to income components and total income. Means, nominal amounts, last calendar year.

Single men, ages 72 to 77 , unweighted.

\begin{tabular}{lcccccccc}
\hline Year & N & $\begin{array}{c}\text { IRA } \\
\text { Withdrawals }\end{array}$ & Earnings & $\begin{array}{c}\text { Pension+ } \\
\text { Annuity }\end{array}$ & $\begin{array}{c}\text { Social } \\
\text { Security } \\
\text { Retirement }\end{array}$ & $\begin{array}{c}\text { Capital } \\
\text { Income }\end{array}$ & $\begin{array}{c}\text { Other } \\
\text { Income* }\end{array}$ & $\begin{array}{c}\text { Total } \\
\text { Income }\end{array}$ \\
\hline 2000 & 242 & 1,372 & 2,227 & 8,223 & 9,308 & 7,303 & 4,913 & 31,975 \\
2002 & 214 & 1,514 & 4,222 & 8,287 & 10,040 & 10,537 & 3,061 & 36,146 \\
2004 & 220 & 1,701 & 4,275 & 7,735 & 10,383 & 6,476 & 2,612 & 31,481 \\
2006 & 241 & 1,924 & 3,017 & 8,147 & 11,175 & 12,254 & 1,720 & 36,312 \\
2008 & 289 & 2,136 & 3,000 & 7,845 & 10,985 & 8,062 & 1,592 & 31,485 \\
2010 & 304 & 1,669 & 3,109 & 5,246 & 12,294 & 6,492 & 2,277 & 29,419 \\
2012 & 310 & 1,567 & 4,292 & 8,019 & 12,943 & 11,608 & 1,769 & 38,631 \\
2014 & 306 & 1,933 & 3,137 & 8,007 & 14,514 & 18,693 & 12,021 & 56,371 \\
\hline
\end{tabular}

Single women, ages 72 to 77 , unweighted.

\begin{tabular}{lcccccccc}
\hline Year & $\mathbf{N}$ & $\begin{array}{c}\text { IRA } \\
\text { Withdrawals }\end{array}$ & Earnings & $\begin{array}{c}\text { Pension+ } \\
\text { Annuity }\end{array}$ & $\begin{array}{c}\text { Social } \\
\text { Security } \\
\text { Retirement }\end{array}$ & $\begin{array}{c}\text { Capital } \\
\text { Income }\end{array}$ & $\begin{array}{c}\text { Other } \\
\text { Income* }\end{array}$ & $\begin{array}{c}\text { Total } \\
\text { Income }\end{array}$ \\
\hline 2000 & 748 & 1,036 & 1,131 & 4,600 & 8,690 & 5,232 & 3,177 & 22,831 \\
2002 & 673 & 1,064 & 1,074 & 5,016 & 9,467 & 3,397 & 1,928 & 20,882 \\
2004 & 700 & 1,130 & 1,296 & 5,441 & 9,820 & 2,988 & 1,283 & 20,827 \\
2006 & 800 & 1,239 & 1,536 & 5,731 & 9,964 & 2,801 & 4,463 & 24,496 \\
2008 & 946 & 1,284 & 1,757 & 7,297 & 10,579 & 7,144 & 1,591 & 28,369 \\
2010 & 947 & 1,294 & 2,214 & 11,631 & 11,440 & 3,701 & 3,992 & 32,979 \\
2012 & 951 & 1,348 & 2,723 & 6,652 & 12,184 & 2,923 & 2,754 & 27,236 \\
2014 & 952 & 1,656 & 2,920 & 6,831 & 13,553 & 4,177 & 4,219 & 31,700 \\
\hline
\end{tabular}

Married and partnered households, at least one person age 72 to 77 , unweighted.

\begin{tabular}{lcccccccc}
\hline Year & N & $\begin{array}{c}\text { HH IRA } \\
\text { Withdrawals }\end{array}$ & $\begin{array}{c}\text { HH } \\
\text { Earnings }\end{array}$ & $\begin{array}{c}\text { HH } \\
\text { Pension+ } \\
\text { Annuity }\end{array}$ & $\begin{array}{c}\text { HH Social } \\
\text { Security } \\
\text { Retirement }\end{array}$ & $\begin{array}{c}\text { HH } \\
\text { Capital } \\
\text { Income }\end{array}$ & $\begin{array}{c}\text { Other HH } \\
\text { Income* }\end{array}$ & $\begin{array}{c}\text { Total HH } \\
\text { Income* }\end{array}$ \\
\hline 2000 & 1,443 & 3,329 & 4,413 & 10,106 & 15,199 & 11,190 & 3,406 & 44,314 \\
2002 & 1,398 & 3,178 & 4,451 & 12,743 & 17,218 & 12,182 & 3,123 & 49,717 \\
2004 & 1,459 & 3,763 & 5,706 & 17,732 & 18,062 & 11,807 & 3,507 & 56,814 \\
2006 & 1,429 & 3,757 & 5,665 & 14,265 & 19,113 & 14,760 & 3,172 & 56,975 \\
2008 & 1,519 & 4,408 & 9,267 & 13,204 & 20,164 & 19,066 & 3,914 & 65,614 \\
2010 & 1,616 & 3,803 & 9,916 & 12,322 & 21,794 & 13,549 & 4,985 & 62,566 \\
2012 & 1,664 & 5,510 & 10,800 & 13,166 & 22,561 & 14,875 & 5,154 & 66,556 \\
2014 & 1,551 & 5,143 & 11,457 & 14,327 & 25,076 & 17,611 & 5,369 & 73,839 \\
\hline
\end{tabular}

Note: Includes married, married/spouse away, partnered.

* Other income $=$ income from $($ SSI + SS Disability + UNEMP + WORKERS COMP + Other Gov Transfer + OTHER)

- Total Income does not include any IRA withdrawals 


\section{References}

Hurd, M. D., E. Meijer, M. Moldoff, and S. Rohwedder (2016). Improved wealth measures in the Health and Retirement Study: Asset reconciliation and cross-wave imputation. Santa Monica, CA: RAND Corporation, Center for the Study of Aging. http://www.rand.org/pubs/working_papers/WR1150.html

Iams, Howard M. and Patrick J. Purcell, 2013, “The Impact of Retirement Account Distributions on Measures of Family Income" Social Security Bulletin, Vol. 73, No. 2

Pantoja, P., et al. (2018). RAND HRS Detailed Imputations File 2014 (V2) Documentation. Santa Monica, CA: RAND Corporation, Center for the Study of Aging. https://www.rand.org/labor/aging/dataprod/income-wealth-imputation.html

RAND HRS Longitudinal File 2014 (V2). Produced by the RAND Center for the Study of Aging, with funding from the National Institute on Aging and the Social Security Administration. Santa Monica, CA (February 2018). 


\section{Appendix}

\section{Appendix 1: Variables to be Included in the RAND HRS Longitudinal File}

The "w" in the variable names/labels refers to the wave number, where HRS $2000=5$, HRS $2002=6$, HRS $2004=7$, etc.

HwIIRAWY1:Ww Income: IRA Withdrawal: Total (last calendar year)

HwIIRAW: Ww Income: IRA Withdrawal: Total (prev 2 yrs/since last int)

HwIOIRAW: Ww Receives: IRA Withdrawal: Total (prev 2 yrs/since last int)

HwIFIRAW: Ww ImpFlag: IRA Withdrawal: Total (prev 2 yrs/since last int)

RwIIRAWY1: Ww Income: R IRA Withdrawal: Total (last calendar year)

RwIIRAW: Ww Income: R IRA Withdrawal: Total (prev 2 yrs/since last int)

RwIOIRAW: Ww Receives: R IRA Withdrawal: Total (prev 2 yrs/since last int)

RwIFIRAW: Ww ImpFlag: R IRA Withdrawal: Total (prev 2 yrs/since last int)

SwIIRAWY1: Ww Income: Sp IRA Withdrawal: Total (last calendar year)

SwIIRAW: Ww Income: Sp IRA Withdrawal: Total (prev 2 yrs/since last int)

SwIOIRAW: Ww Receives: Sp IRA Withdrawal: Total (prev 2 yrs/since last int)

SwIFIRAW: Ww ImpFlag: Sp IRA Withdrawal: Total (prev 2 yrs/since last int) 
Variables to be Included in the RAND HRS Detailed Imputations File

HwIIRAWY1:Ww Income: IRA Withdrawal: Total (last calendar year)

HwIIRAW1Y1: $\quad$ Ww IncPart: IRA Withdrawal: Account \#1 (last calendar year)

HwIIRAW2Y1: $\quad$ Ww IncPart: IRA Withdrawal: Account \#2 (last calendar year)

HwIIRAW3Y1: $\quad$ Ww IncPart: IRA Withdrawal: Account \#3 (last calendar year)

HwIIRAW4Y1: $\quad$ Ww IncPart: IRA Withdrawal: Account \#4 (cash-in) (last calendar year)

HwIIRAW: Ww Income: IRA Withdrawal: Total (prev 2 yrs/since last int)

HwIIRAW1: Ww IncPart: IRA Withdrawal: Account \#1 (prev 2 yrs/since last int)

HwIIRAW2: Ww IncPart: IRA Withdrawal: Account \#2 (prev 2 yrs/since last int)

HwIIRAW3: Ww IncPart: IRA Withdrawal: Account \#3 (prev 2 yrs/since last int)

HwIIRAW4: Ww IncPart: IRA Withdrawal: Account \#4 (cash-in) (prev 2 yrs/since last int)

HwIOIRAW: Ww Receives: IRA Withdrawal: Total (prev 2 yrs/since last int)

HwIOIRAW1:Ww Receives: IRA Withdrawal: Account \#1 (prev 2 yrs/since last int)

HwIOIRAW2: Ww Receives: IRA Withdrawal: Account \#2 (prev 2 yrs/since last int)

HwIOIRAW3:Ww Receives: IRA Withdrawal: Account \#3 (prev 2 yrs/since last int)

HwIOIRAW4: Ww Receives: IRA Withdrawal: Account \#4 (cash-in) (prev 2 yrs/since last int)

HwIFIRAW: Ww ImpFlag: IRA Withdrawal: Total (prev 2 yrs/since last int)

HwIFIRAW1: Ww ImpFlag: IRA Withdrawal: Account \#1 (prev 2 yrs/since last int)

HwIFIRAW2: Ww ImpFlag: IRA Withdrawal: Account \#2 (prev 2 yrs/since last int)

HwIFIRAW3: Ww ImpFlag: IRA Withdrawal: Account \#3 (prev 2 yrs/since last int)

HwIFIRAW4: Ww ImpFlag: IRA Withdrawal: Account \#4 (cash-in) (prev 2 yrs/since last int) 
RwIIRAWY1: Ww Income: R IRA Withdrawal: Total (last calendar year)

RwIIRAW1Y1: $\quad$ Ww IncPart: R IRA Withdrawal: Account \#1 (last calendar year)

RwIIRAW2Y1: $\quad$ Ww IncPart: R IRA Withdrawal: Account \#2 (last calendar year)

RwIIRAW3Y1: $\quad$ Ww IncPart: R IRA Withdrawal: Account \#3 (last calendar year)

RwIIRAW4Y1: $\quad$ Ww IncPart: R IRA Withdrawal: Account \#4 (cash-in) (last calendar year)

RwIIRAW: Ww Income: R IRA Withdrawal: Total (prev 2 yrs/since last int)

RwIIRAW1: Ww IncPart: R IRA Withdrawal: Account \#1 (prev 2 yrs/since last int)

RwIIRAW2: Ww IncPart: R IRA Withdrawal: Account \#2 (prev 2 yrs/since last int)

RwIIRAW3: Ww IncPart: R IRA Withdrawal: Account \#3 (prev 2 yrs/since last int)

RwIIRAW4: Ww IncPart: R IRA Withdrawal: Account \#4 (cash-in) (prev 2 yrs/since last int)

RwIOIRAW: Ww Receives: R IRA Withdrawal: Total (prev 2 yrs/since last int)

RwIOIRAW1: Ww Receives: R IRA Withdrawal: Account \#1 (prev 2 yrs/since last int)

RwIOIRAW2: Ww Receives: R IRA Withdrawal: Account \#2 (prev 2 yrs/since last int)

RwIOIRAW3: Ww Receives: R IRA Withdrawal: Account \#3 (prev 2 yrs/since last int)

RwIOIRAW4: Ww Receives: R IRA Withdrawal: Account \#4 (cash-in) (prev 2 yrs/since last int)

RwIFIRAW: Ww ImpFlag: R IRA Withdrawal: Total (prev 2 yrs/since last int)

RwIFIRAW1: Ww ImpFlag: R IRA Withdrawal: Account \#1 (prev 2 yrs/since last int)

RwIFIRAW2: Ww ImpFlag: R IRA Withdrawal: Account \#2 (prev 2 yrs/since last int)

RwIFIRAW3: Ww ImpFlag: R IRA Withdrawal: Account \#3 (prev 2 yrs/since last int)

RwIFIRAW4: Ww ImpFlag: R IRA Withdrawal: Account \#4 (cash-in) (prev 2 yrs/since last int) 
SwIIRAWY1: Ww Income: Sp IRA Withdrawal: Total (last calendar year)

SwIIRAW1Y1: $\quad$ Ww IncPart: Sp IRA Withdrawal: Account \#1 (last calendar year)

SwIIRAW2Y1: $\quad$ Ww IncPart: Sp IRA Withdrawal: Account \#2 (last calendar year)

SwIIRAW3Y1: $\quad$ Ww IncPart: Sp IRA Withdrawal: Account \#3 (last calendar year)

SwIIRAW4Y1: $\quad$ Ww IncPart: Sp IRA Withdrawal: Account \#4 (cash-in) (last calendar

year)

SwIIRAW: Ww Income: Sp IRA Withdrawal: Total (prev 2 yrs/since last int)

SwIIRAW1: Ww IncPart: Sp IRA Withdrawal: Account \#1 (prev 2 yrs/since last int)

SwIIRAW2: Ww IncPart: Sp IRA Withdrawal: Account \#2 (prev 2 yrs/since last int)

SwIIRAW3: Ww IncPart: Sp IRA Withdrawal: Account \#3 (prev 2 yrs/since last int)

SwIIRAW4: Ww IncPart: Sp IRA Withdrawal: Account \#4 (cash-in) (prev 2 yrs/since last int)

SwIOIRAW: Ww Receives: Sp IRA Withdrawal: Total (prev 2 yrs/since last int)

SwIOIRAW1: Ww Receives: Sp IRA Withdrawal: Account \#1 (prev 2 yrs/since last int)

SwIOIRAW2: Ww Receives: Sp IRA Withdrawal: Account \#2 (prev 2 yrs/since last int)

SwIOIRAW3: Ww Receives: Sp IRA Withdrawal: Account \#3 (prev 2 yrs/since last int)

SwIOIRAW4: Ww Receives: Sp IRA Withdrawal: Account \#4 (cash-in) (prev 2 yrs/since last int)

SwIFIRAW: Ww ImpFlag: Sp IRA Withdrawal: Total (prev 2 yrs/since last int)

SwIFIRAW1: Ww ImpFlag: Sp IRA Withdrawal: Account \#1 (prev 2 yrs/since last int)

SwIFIRAW2: Ww ImpFlag: Sp IRA Withdrawal: Account \#2 (prev 2 yrs/since last int)

SwIFIRAW3: Ww ImpFlag: Sp IRA Withdrawal: Account \#3 (prev 2 yrs/since last int)

SwIFIRAW4: Ww ImpFlag: Sp IRA Withdrawal: Account \#4 (cash-in) (prev 2 yrs/since last int) 


\section{Appendix 2: Computation of Required Minimum Distributions (RMDs)}

The question sequence that asks respondents about the first, second, and third (or all other) IRAs includes direct questions about whether they took the RMD. We do not make any effort to fill responses of "8" (Don't Know), "9" (Refused), or missing (.) to this question. Rather, we use whatever information is provided. If the respondent affirms taking the RMD and the withdrawal amount is missing we replace the missing value with the computed RMD. ${ }^{8}$

\section{Calculating the RMD}

Several pieces of information are required in order to calculate the RMD. These include: (1) marital status; (2) the age of the respondent and their spouse (if applicable) during the tax year; (3) the life expectancy tables in IRS Publication 590 (or 590-B as of tax year 2014); and (4) the IRA balance(s) on December $31^{\text {st }}$ of the year prior to when the RMD must be taken.

There are a small number of cases in each wave that have missing marital statuses. We treat these as single. There are also a small percentage of cases in each wave where the spouse or partner did not respond. For these, we assume that the marital status for both members of the couple is the same.

There are two key age cutoffs that are useful for determining the RMD: whether the respondent and/or their spouse (if applicable) turned 701/2 years of age, or were greater than (or equal to) 71 years of age during the tax year. There are a small number of cases where the respondent's age is unknown. For those whose marital status is defined as "married" (or "married, spouse absent"), we use the age given for the other member of the couple. ${ }^{9}$ In

\footnotetext{
${ }^{8}$ There is a small percentage of individuals in each wave who are under the age of $701 / 2$, but still report taking the "minimum withdrawal option" to avoid a tax penalty. It could be that this question was unclear to these respondents. We ignore their answers, since they are under no obligation to take the RMD.

${ }^{9}$ In all cases where this was done, the financial respondent's age was used to fill that of their nonresponding spouse.
} 
noncoupled households, the age of the respondent is never missing. For couples, since the financial respondent is the one who answers questions regarding IRAs for everyone in the household, the spouse or partner's age is based on when the financial respondent was interviewed.

With regard to the life expectancy tables found in IRS Publication 590 (or 590-B as of tax year 2014), there are two that we use for the purpose of calculating the RMD: Table II (Joint Life and Last Survivor Expectancy), and Table III (Uniform Lifetime Table, or the Table for Determining Applicable Divisor for Minimum Distribution Incidental Benefit prior to tax year 2001). We examined these two tables for the tax years of interest (1999 to 2014), and found the figures to be the same from 1999 to $2001,{ }^{10}$ and they then changed in 2002. As of tax year 2014, no updates have been made, so the figures are the same for tax years 2002 to 2014. To calculate the RMD, we use Table II if the IRA owner is "married" (or "married, spouse absent") and is more than 10 years older than their spouse. Otherwise, we use Table III.

IRA balances for up to three IRA or Keogh accounts are reported in the HRS survey, reflecting the value at the time of interview. As part of the RAND HRS data development effort, any missing values in IRA/Keogh balances have been imputed. The RMD calculation, however, requires that we know the IRA balance(s) on December $31^{\text {st }}$ of the year prior to when the RMD must be taken. Moreover, unlike many of the income questions in the HRS survey that ask about income received last calendar year, the questions about IRA withdrawals focus on the period since the last interview, or in the past two years (for new interviewees). The one exception is the question asking whether the "minimum withdrawal option" was taken to avoid a tax penalty.

\footnotetext{
${ }^{10}$ For tax years 1999 to 2001, there are no figures in Table II for: (1) anyone $<35$ years of age; (2) IRA owners ages 93 to 115 with spouses who are age 35 - 54; or (3) spouses $>94$ years of age. We, therefore, fill in these figures with information from IRA Publication 939 (General Rule for Pensions and Annuities), specifically Table VI (Ordinary Joint Life and Last Survivor Annuities Two Lives - Expected Return Multiples) if necessary.
} 
Here, no time frame is specified. Since individuals who are required to take RMDs must do so each year, we assume that a "yes" answer to this question means that the RMD was taken last calendar year. To calculate the RMD for last calendar year, we do the following:

1. Assume the total of all IRA account balances at the end of year $\mathrm{T}-2=\mathrm{X}$; this is December $31^{\text {st }}$ of the year prior to when the RMD must be taken.

2. Given a value of $\mathrm{X}$, the RMD can be computed as, say, $\mathrm{R}(\mathrm{X})$.

3. According to IRS Publication 590 (or 590-B as of tax year 2014), R(X) $=\mathrm{r} * \mathrm{X}$, where $r=1 /$ life expectancy factor (from Table II or Table III).

4. Therefore, at the end of the previous calendar year, the balance is $X-R(X)=X-r$ $* X=(1-r) * X$. If they do the same this year, we can reasonably assume they do it at the end of the year, so the current balance is $\mathrm{Y}=(1-\mathrm{r}) * \mathrm{X}$.

5. We have the total of all IRA account balances "at the present time," either reported or imputed. So, we have a value of $\mathrm{Y}$ and $\mathrm{r}$, and can compute $\mathrm{X}$ as a result. From this we can compute R.

6. Specifically, the total RMD is $(\mathrm{r} /(1-\mathrm{r})) * \mathrm{Y}$.

\section{Evaluating the RMD}

We first create the following summary measures for IRA withdrawals, and convert the resulting values to reflect amounts received last calendar year:

$A=($ Sum of all continuous values (reported and imputed) / \# months since the last interview) $* 12$

$L=($ Sum of all continuous and lower bracket values (reported) / \# months since the last interview) $* 12$.

$H=($ Sum of all continuous and upper bracket values (reported) / \# months since the last interview) $* 12$. 
For the spouse or partner versions of these measures, the denominator is the number of months since the financial respondent's last interview, since the financial respondent is the one who answers the IRA questions for everyone in the household.

To evaluate the RMD, and assign the total withdrawal amount (TOTW) for both the respondent and their spouse or partner (if applicable), we use the following rules ${ }^{11}$ :

For those who made no withdrawals:

$\mathrm{TOTW}=0$

For those who are $>=701 / 2$ years of age, and reported taking the $R M D$ for one or more

IRAs:

if $(\mathrm{L}<=\mathrm{RMD}<=\mathrm{H})$ then TOTW $=\mathrm{RMD}$

otherwise if $\mathrm{RMD}>\mathrm{H}$ then TOTW $=\mathrm{H}$ (which is closest to the RMD)

otherwise if $\mathrm{RMD}<\mathrm{L}$ then TOTW $=\mathrm{L}$ (which is closest to the $\mathrm{RMD}$ )

For everyone else:

$\mathrm{TOTW}=\mathrm{A}$

\footnotetext{
${ }^{11}$ Most respondents who cashed in any IRA or Keogh accounts have no other withdrawals, so questions about the RMD are never asked. For respondents who have at least one other withdrawal and report taking the RMD, the RMD does not change, because the current balance of any cashed-in accounts is zero.
} 